\title{
Chimeric Antigen Receptor T-Cell Therapy: Are Neuroradiologists Prepared?
}

I: read with interest the Practice Vignette by Valand et al with regard to neurotoxicity of chimeric antigen receptor $\mathrm{T}$-cell (CAR T) therapy for hematologic cancers. ${ }^{1}$ The authors concluded that brain MR imaging is unremarkable in mild forms of neurotoxicity and only demonstrates nonspecific findings in the context of severe neurotoxicity, which can resemble chronic microvascular ischemia and migraine. While I agree that the imaging findings are not pathognomonic, 2 case series in patients with severe CD19-directed CAR T-induced neurotoxicity showed similar imaging findings of bilateral thalamic and brain stem involvement with extension to the basal gangRlia and extreme capsule, resembling central-variant posterior reversible encephalopathy syndrome or acute necrotizing encephalopathy in a subset of patients. ${ }^{2,3}$ Another reported imaging finding was transient lesions of the splenium of the corpus callosum characterized by restricted diffusion and $\mathrm{T} 2$ prolongation with resolution on subsequent imaging. ${ }^{2}$ In addition, a recent study indicated restricted diffusion in the bilateral occipital cortex, which demonstrated hypometabolism on subsequent FDG-PET imaging. ${ }^{3}$ Considering that all the available studies only reported findings on conventional MR imaging, it should not be surprising that the authors detected abnormalities only in a subset of patients with severe neurotoxicity.

CAR T therapy neurotoxicity represents a continuum ranging from different degrees of neurotoxicity to severe brain edema in lethal cases, which is corroborated by postmortem studies. ${ }^{2,3}$ Santomasso et $\mathrm{al}^{2}$ analyzed excitatory agonists such as glutamate (Glut) and quinolinic acid (QA) in the CSF of 13 patients receiving CD19-directed CAR T treatment and demonstrated a significant increase in Glut and QA CSF levels during neurotoxicity compared with pretreatment. In addition, Gust et $\mathrm{al}^{3}$ demonstrated increased CSF levels of S100 calcium binding protein $\mathrm{B}$ and glial fibrillary acidic protein in patients with neurotoxicity, indicating astrocyte injury, which would explain the presence of cerebral edema, given the key role of glial cells in osmotic regulation in the brain.

In conclusion, neuroradiologists should have a high level of suspicion for CAR T therapy neurotoxicity in patients with bilateral thalamic and brain stem involvement. Designing prospective studies with advanced MR imaging sequences focusing on the detection of early brain edema would be crucial to better understand this entity and discover early imaging findings of CAR $\mathrm{T}$ therapy neurotoxicity.

\section{REFERENCES}

1. Valand HA, Huda F, Tu RK. Chimeric antigen receptor t-cell therapy: what the neuroradiologist needs to know. AJNR Am J Neuroradiol 2019;40:766-68 CrossRef Medline

2. Santomasso BD, Park JH, Salloum D, et al. Clinical and biological correlates of neurotoxicity associated with CAR $t$-cell therapy in patients with b-cell acute lymphoblastic leukemia. Cancer Discov 2018;8:958-71 CrossRef Medline

3. Gust J, Finney OC, Li D, et al. Glial injury in neurotoxicity after pediatric cd19-directed chimeric antigen receptor $\mathbf{t}$ cell therapy. Ann Neurol 2019;86:42-54 CrossRef Medline

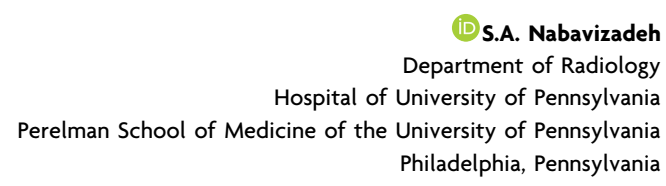

(i) S.A. Nabavizadeh Department of Radiology

http://dx.doi.org/10.3174/ajnr.A6186 